\title{
Peran Kepala Sekolah Sebagai Supervisor Kinerja Guru Bimbingan dan Konseling
}

\author{
Muhammad Eka Prasetia \\ Universitas Islam Kalimantan M.A.B Banjarmasin \\ ekajurnalpp@gmail.com
}

\begin{abstract}
This study aims to determine the description of the role of the principal as a supervisor in improving the performance of Guidance and Counseling Teachers at SMA Negeri 10 Banjarmasin City. The approach in this study uses a qualitative approach with a phenomenological research design. The method used in this study in collecting data is to use interview and documentation techniques, which will then be analyzed and seen for the validity of the data using data triangulation techniques. The results obtained based on data collected through interviews and documentation found that the Principal of SMA Negeri 10 Banjarmasin has carried out his roles and functions as well as duties and responsibilities as school supervisors by carrying out planned and scheduled supervision of guidance and counseling teachers in improving their performance. In addition, based on the data collected through interviews and documentation, it is known that the supervision technique used by the Principal of SMA Negeri 10 Banjarmasin is an individual technique using 3 supervision activities, namely, class visits, class observations and individual interviews.
\end{abstract}

Keywords: Principal; supervisor; counseling guidance teacher

\begin{abstract}
Abstrak
Penelitian ini bertujuan untuk mengetahui Gambaran Peran Kepala sekolah sebagai supervisor dalam peningkatan Kinerja Guru Bimbingan dan Konseling di SMA Negeri 10 Kota Banjarmasin. Pendekatan dalam penelitian ini menggunakan pendekatan kualitatif dengan desain penelitian fenomenologi. Adapun metode yang dipakai pada penelitian ini dalam mengumpulkan data adalah menggunakan tekhnik wawancara dan dokumentasi, yang kemudian
\end{abstract}


akan dianalisis dan di lihat keabsahan datanya dengan menggunakan teknik triangulasi data. Hasil penelitian yang didapat berdasarkan data yang dikumpulkan melalui wawancara dan dokumentasi di temukan bahwa Kepala Sekolah SMA Negeri 10 Banjarmasin sudah menjalankan peran dan fungsinya serta tugas dan tanggung jawab sebagai supervisor sekolah dengan melakukan supervise yang terencana dan terjadwal terhadap guru bimbingan dan konseling dalam peningkatan kinerja mereka. Selain itu berdasarkan data yang dikumpulkan juga melalui wawancara dan dokumentasi diketahui bahwa teknik supervisi yang di gunakan oleh Kepala Sekolah SMA Negeri 10 Banjarmasin adalah teknik individual/perorangan dengan menggunakan 3 kegiatan supervisi yaitu, kunjungan kelas, observasi kelas dan wawancara perseorangan.

Kata kunci: Kepala sekolah; supervisor; guru bimbingan konseling

\section{Pendahuluan}

Dalam paradigma baru manajemen pendidikan, kepala sekolah sedikitnya harus berfungsi sebagai edukator, manajer, administrator, supervisor, leader, inovator dan motivator yang singkat EMASLIM. ${ }^{1}$ Dari tujuh peran yang harus dimiliki oleh kepala sekolah ada satu peran sebagai penggerak jalannya proses kegiatan lembaga pendidikan dengan baik yaitu peran kepala sekolah sebagai supervisor, ${ }^{2}$ karena sebagai supervisor atau pengawas sangat berkaitan langsung dengan proses pelaksanaan tugas-tugas yang dilakukan oleh sumber daya sekolah.

Kepala sekolah selaku supervisor di samping harus menguasai teori administrasi pendidikan dan pengetahuan tentang supervisi juga memerlukan teknik supervisi tertentu dalam melaksanakan tugas supervisinya. ${ }^{3}$ Supervisi yang baik mengarahkan perhatiannya kepada dasar-dasar pendidikan dan cara-cara belajar serta cara berkembangnya dalam pencapaian tujuan umum pendidikan.

Kepala sekolah selaku supervisor dalam usahanya memberikan bantuan atau pelayanan profesional kepada guru selalu menaruh perhatian yang sungguhsungguh terhadap aspek-aspek yang dapat mengganggu tugas guru dalam proses

${ }^{1}$ Nurfarida, S. F., \& Minsih, S. A. (2017). Kepemimpinan Kepala Sekolab Dalam Melaksanakan Program Pengembangan Sekolah Di SDIT Muhammadiyah Al-Kautsar Gumpang Tabun Ajaran 2016/2017 (Doctoral dissertation, Universitas Muhammadiyah Surakarta).

2 Raupu, S., \& Arifanti, D. R. (2019). Pelaksanaan Supervisi Pendidikan oleh Kepala Sekolah dalam Meningkatkan Profesionalisme Guru Bimbingan Konseling di SMP Negeri 8 Palopo. Kelola: Journal of Islamic Education Management, 4(1), 61-66.

3 Bowo, B. (2020). Peran Kepemimpinan Kepala Sekolah Sebagai Supervisor dalam Meningkatkan Kompetensi Guru di SMA Negeri 1 Ngronggot Kabupaten Nganjuk Tahun 2020. Dharma Pendidikan, 15(2), 93-106. 
belajar mengajar dan melaksanakan layanan bimbingan dan konseling. ${ }^{4}$ Dalam hal ini, kepala sekolah senantiasa mempelajari secara obyektif dan terus menerus masalah-masalah yang menjadi kendala guru dalam pelaksanaan tugasnya.

Oleh karena itu dengan adanya supervisi yang dilaksanakan kepala sekolah ini merupakan kontrol agar kegiatan pendidikan di sekolah terarah pada tujuan yang telah ditetapkan. ${ }^{5}$ Pengawasan dan pengendalian juga merupakan tindakan preventif untuk mencegah agar para tenaga kependidikan tidak melakukan penyimpangan dan lebih berhati-hati dalam melaksanakan pekerjaan sehingga menjadi lebih disiplin dalam bekerja dan profesional.

Selain itu keberadaan supervisi diharapkan menjadi motivator bagi guruguru terutama guru bimbingan dan konseling untuk dapat bekerja dengan baik dan bersemangat untuk mempersiapkan siswa dalam menghadapi kehidupan masa depan. ${ }^{6}$ Apabila guru di motivasi, maka diharapkan suasana sekolah akan lebih bergairah. Guru-guru pada akhirnya dapat bekerja dengan tenang, lebih tekun, tugas dan tanggung jawabnya dihadapi dengan senang hati, tidak mudah bosan apalagi putus asa ataupun menggerutu.

Supervisi terhadap guru dimaksudkan untuk melakukan pembinaan dan pengembangan terhadap guru sebagai salah satu komponen sekolah. Hasil penelitian yang dilakukan oleh Fadhli berkaitan dengan kinerja kepala sekolah menyatakan bahwa kepala sekolah yang berhasil adalah kepala yang memiliki komitmen yang kuat terhadap peningkatan kualitas akademik. ${ }^{7}$ Komitmen yang kuatn menggambarkan adanya kemauan dan kemampuan melakukan monitoring pada semua aktivitas personel sekolah. Oleh karena itu agar diperoleh kualitas pendidikan yang sesuai dengan tujuan yang telah ditetapkan maka guru dituntut untuk selalu memiliki kinerja yang tinggi.

Kepala sekolah sebagai pimpinan pendidikan di sekolah memiliki peran sebagai supervisor yang bertugas membina sekolah agar dapat mencapai tujuan pendidikan. Kepala sekolah dapat melakukan supervisi dengan cara pengawasan dan pengendalian untuk meningkatkan kinerja guru disekolahnya terutama kinerja guru bimbingan dan konseling. ${ }^{8}$

${ }^{4}$ Salma, P., \& Yusrizal, N. U. (2018). Pelaksanaan Supervisi klinis dalam Meningkatkan Kompetensi Profesional Guru di MAN Beureunuen. Jurnal Administrasi Pendidikan: Program Pascasarjana Unsyiah, 6(1).

${ }^{5}$ Ginting, R. (2020). Fungsi Supervisi Kepala Sekolah Terhadap Kinerja Guru. JURNAL Edukasi Nonformal, 1(2), 88-93.

${ }^{6}$ Jihad, A., \& Murniati, A. R. (2019). Hubungan motivasi kerja dan supervisi kepala sekolah dengan kinerja guru SMP Negeri di Kecamatan Babahrot Aceh Barat Daya. Jurnal Administrasi Pendidikan: Program Pascasarjana Unsyiah, 7(1).

7 Fadhli, M. (2016). Kepemimpinan Kepala Sekolah Yang Efektif dalam Menciptakan Sekolah Efektif. Jurnal Tarbiyah, 23(1).

8 Anggraini, S. (2017). Peran supervisi bk untuk meningkatkan profesionalisme guru Bk. In Prosiding Seminar Bimbingan dan Konseling (Vol. 1, No. 1, pp. 332-341). 
Seperti yang diketahui bahwa Bimbingan dan konseling merupakan bagian penting dalam penyelenggaraan pendidikan. ${ }^{9}$ Tercapainya tujuan pendidikan tidak terlepas dari beberapa kegiatannya, beberapa kegiatan dalam bimbingan dan konseling sangat memberikan kontribusi yang positif bagi perkembangan siswa. Rahman menyatakan bahwa "bimbingan adalah bantuan yang diberikan kepada seseorang agar ia mampu memahami diri dan mengembangkan diri sehingga mencapai kehidupan yang sukses dan bahagia". ${ }^{10}$ Natawijaya menyatakan bahwa "bimbingan adalah bantuan yang diberikan oleh seseorang baik pria maupun wanita yang memiliki pribadi yang baik dan pendidikan yang memadai, kepada seseorang individu dari setiap usia untuk menolongnya mengembangkan kegiatan-kegiatan hidupnya sendiri, membuat pilihan sendiri dan memikul bebannya sendiri", ${ }^{11}$

Tujuan akhir dari bimbingan dan konseling adalah memandirikan siswa. Bimbingan dan konseling merupakan bagian dari pendidikan yang membantu tercapainya tujuan pendidikan. Ranah garapan bidang Bimbingan dan Konseling meliputi 4 bidang bimbingan yaitu: (1) pribadi, (2) sosial, (3) belajar, (4) karir. ${ }^{12}$ Bimbingan dan konseling bukanlah pelayanan eksklusif yang harus terpisah dari pendidikan. Keberadaan bimbingan dan konseling dalam dunia pendidikan bukan sesuatu yang dipaksakan, karena bimbingan dan konseling merupakan konsekuensi logis dari hakikat pendidikan itu sendiri.

Dalam perspektif historis, eksistensi bimbingan dan konseling dalam dunia pendidikan Indonesia mulai dirintis pada pertengahan tahun enam puluhan. Dalam kurun waktu lebih dari empat puluh tahun tersebut, perkembangan bimbingan dan konseling telah melewati beberapa periode yaitu dekade 60-an (perintisan), dekade 70-an (penataan), dekade 80-an (pemantapan), dan dekade 90 -an (profesionalisasi). ${ }^{13}$ Walaupun demikian, profesi bimbingan dan konseling masih dirundung banyak masalah terutama pada tataran praktisnya dan kinerjanya.

Oleh karena itu sangat penting diadakan supervisi terhadap kinerja guru Bimbingan dan konseling dimana guru bimbingan dan konseling sebagai

9 Suwidagdho, D., Lestari, L., \& Dewi, S. P. (2017). Peran Pengawas BK untuk Meningkatkan Profesionalitas Guru Bimbingan dan Konseling. In Prosiding Seminar Bimbingan dan Konseling (Vol. 1, No. 1, pp. 137-143).

10 Fathur Rahman. (2009). Bimbingan dan Konseling Komprehensif; Dari Paradigma Menuju Aksi. Disampaikan pada Workshop Penyusunan Program BK Komprehensif bertempat di Ruang Sidang Utama Rektorat UNY, Kerjasama Prodi BK UNY dan PD ABKIN DIY. Yogyakarta: Universitas Negeri Yogyakarta.

11 Natawidjaja, Rochman, (2009).Konseling Kelompok (Konsep Dasar dan Pendekatan),Bandung: Rizqi Press,

12 Sutarto, S., Syafriyadin, S., \& Warlizasusi, J. (2019). Konseling Eklektik Islami untuk Mengubah Konsep Diri Waria. KONSELI: Jurnal Bimbingan dan Konseling (E-Journal), 6(1), 65-74.

${ }^{13}$ Vianda, D. (2015). Bimbingan dan Konseling dalam Pendidikan Formal. Jurnal Al-Taujih: Bingkai Bimbingan dan Konseling Islami, 1(1), 98-108. 
pemimpin dan manajer dalam layanan bimbingan dan konseling mempunyai peran dan tanggung jawab yang strategis terhadap keberhasilan pencapaian tujuan siswa. ${ }^{14}$ Supervisi ini akan lebih baik dilakukan langsung oleh kepala sekolah, mengingat kepala sekolah selain memimpin juga sebagai supervisor, sehingga peran dan tanggung jawab tersebut menuntut guru bimbingan dan konseling untuk menunjukkan kinerja yang profesional

Menurut Mangkunegara, kinerja (prestasi kerja) adalah hasil kerja secara kualitas dan kuantitas yang dicapai oleh seseorang pegawai dalam melaksanakan tugasnya sesuai dengan tanggang jawab yang diberikan kepadanya. ${ }^{15}$ Tapi faktanya masih banyak guru bimbingan dan konseling yang belum maksimal dalam menjalankan kinerjanya sebagai guru Bimbingan dan konseling. Hal ini di buktikan dengan dijumpainya berbagai kritikan, keluhan, dan komentar miring dari peserta didik, tenaga kependidikan lain dan stakeholders melalui ungkapan "guru $\mathrm{BK} / \mathrm{K}$ di sekolah tidak siap pakai, guru $\mathrm{BK} / \mathrm{K}$ sebagai polisi sekolah, kegiatan bimbingan tidak perlu diikuti peserta didik karena tidak ada nilainya, dan pekerjaan utama guru $\mathrm{BK} / \mathrm{K}$ adalah mencari kesalahan dan mengatasi masalah peserta didik yang "nakal", melanggar aturan sekolah dan bermasalah.

Hasil penelitian Hajati menunjukkan sebagian besar guru Bimbingan dan Konseling/Konselor kurang menguasai kompetensi teoretik pada keseluruhan rumpun kompetensi, mereka sangat kurang dalam mengembangkan profesionalnya sebagai konselor secara berkelanjutan. Dari penelitian tersebut diperoleh data bahwa penguasaan kompetensi konselor pada: (1) sikap, nilai, dan disposisi kepribadian yang mendukung berada pada kategori kurang (62\%); (2) mengenal secara mendalam konseli yang hendak dilayaniberada pada kategorikurang (84\%); (3) menguasai kerangka teoretik BK berada pada kategori rendah (60\%); (4) menyelenggarakan layanan BK yang memandirikan berada pada kategori kurang (64\%); dan (5) mengembangkan profesionalitas secara berkelanjutan berada pada kategorirendah $(54 \%){ }^{16}$

Penelitian ini menggunakan metode kualitatif dengan desain penelitian fenomenologi yang berbentuk deskriptif yang tujuannya adalah untuk mendeskripsikan, menggambarkan atau melukiskan objek yang diteliti secara sistematis, faktual dan akurat mengenai fakta-fakta, sifat-sifat serta fenomena yang diselidiki.

14 Permana, S. A. (2020). Peran Guru BK dalam Meningkatkan Keterampilan Belajar dan Motivasi Belajar Siswa. Syifaul Qulub: Jurnal Bimbingan dan Konseling Islam, 1(2), 61-69. Bandung

${ }^{15}$ Mangkunegara. (2011). Manajemen Sumber Daya Perusahaan. PT.Remaja Rosdakarya.

${ }^{16}$ Hajati, K. (2010) Model Program peningkatan kompetensi konselor sekolah menengah atas berbasis standar kompetensi konselor Indonesia. Disertasi Doktor pada SPS UPI Bandung: tidak diterbitkan 
Sugiyono menjelaskan bahwa penelitian kualitatif adalah metode penelitian yang berlandaskan pada filsafat postpositivisme, digunakan untuk meneliti pada kondisi obyek yang alamiah, (sebagai lawannya adalah eksperimen) dimana peneliti adalah sebagai instrument kunci. Penelitian bertujuan menggali atau membangun suatu proporsi atau menjelaskan makna dibalik realita. ${ }^{17}$ Peneliti berpijak dari realita atau peristiwa yang berlangsung di lapangan. Adapun yang dijadikan subjek dalam penelitian ini adalah Kepala Sekolah dan Guru Bimbingan dan Konseling SMA Negeri 10 Banjarmasin. Penentuan kepala sekolah sebagai subjek penelitian karena untuk mengetahui bagaimana perjalanan selama menjadi kepala sekolah yang bertanggung jawab dan juga orang yang mengambil keputusan penuh terhadap segala kegiatan yang berkaitan dengan sekolah salah satunya sebagai supervisor internal.pengumpulan data yang dilakukan oleh peneliti adalah dengan wawancara

Teknik keabsahan data yang digunakan dalam penelitian ini adalah triangulasi. Peneliti mengumpulkan data sejenis dari berbagai sumber data yang berbeda-beda, dimana kebenaran data yang didapatkan dari salah satu informan akan di konfirmasikan dengan data yang di peroleh dari informan yang lain. Dengan teknik ini diharapkan akan diperoleh data-data yang terbukti keabsahannya sehingga hasil penelitian dapat di terapkan.

Di dalam pengumpulan data yang digunakan adalah teknik wawancara dan dokumentasi. adapun jenis-jenis instrumen penelitian yang peneliti gunakan adalah sebagai berikut:

1. Lembar wawancara, yaitu sejumlah pertanyaan pokok yang diajukan sebagai panduan untuk bertanya kepada subyek penelitian untuk mendapatkan informasi yang mendetil tentang Peran Kepala Sekolah Sebagai Supervisor Dalam Peningkatan Kinerja Guru Bimbingan dan Konseling di SMA Negeri 10 Banjarmasin.

2. Lembar dokumentasi, yaitu data-data tertulis yang diperoleh mengenai kunjungan kelas pada saat guru Bimbingan dan Konseling memberikan Layanan Informasi dan pertemuan individual dalam perbaikan pengajaran atau pemberian konseling pada siswa.

Menurut Miles and Hubberman analisis data dilaksanakan dengan mencari dan menyusun secara sistematis data yang diperoleh dari hasil wawancara, catatan lapangan, dan dokumentasi, dengan cara mengorganisasikan data, menjabarkannya ke dalam unit-unit, melakukan sintesa, menyusun kedalam pola, memilih mana yang penting dan yang akan dipelajari, dan membuat kesimpulan sehingga mudah dipahami oleh diri sendiri maupun orang lain

${ }^{17}$ Sugiyono.(2015) Metode Penelitian Pendidikan Pendekatan kuantitatif, Kualitatif, dan R\&D, (Bandung: Alfabeta). 


\section{Hasil dan Pembahasan}

Hasil-hasil penelitian yang di temukan peneliti Berdasarkan rumusan masalah yang dikemukakan yaitu hanya mengetahui gambaran peran kepala sekolah dalam supervisi kinerja guru BK serta tekhnik apa yang digunakan dalam melaksanakan supervisi hasil penggalian informasi dilakukan oleh peneliti yaitu;

Pertama, dapat diketahui bahwa gambaran peran kepala sekolah sebagai supervisor sekolah di SMA Negeri 10 Banjarmasin dalam melakukan supervisi sudah sesuai dengan peran dan tugas serta tanggung jawabnya sebagai supervisor sekolah, karena sebelum melaksanakan supervisi kepala sekolah terlebih dahulu membuata perencanaan apa saja yang akan di supervisi nanti untuk peningkatan kinerja guru bimbingan dan konseling yang kemudian perencanaan tersebut di buat terjadwal untuk melaksanakan supervisi.

Kedua, Teknik yang digunakan oleh Kepala Sekolah SMA Negeri 10 banjarmasin sebelum pandemic covid adalah teknik individual yaitu dengan cara melakukan observasi kelas dan kunjungan kelas serta wawancara perseorangan ketika guru bimbingan dan konseling melakukan layanan akan tetapi setelah pandemic covid 19 melanda Banjarmasin Kepala Sekolah mengatakan untuk kunjungan ke kelas, dan observasi kelas tidak lagi dilakukan tetapi hanya melakukan wawancara perseorangan melalui daring.Berdasarkan laporan kinerja yang dikumpulkan oleh Guru Bimbingan dan Konseling.

Berdasarkan hasil penelitian diatas dapat diketahui bahwa peran beliau sebagai kepala sekolah bukan hanya memimpin tapi juga sebagai supervisor sekolah, dimana sebagai supervisor sekolah kepala sekolah berkewajiban melakukan supervisi disekolah yang dipimpin, hal ini sesuai dengan pendapat Herabudin, yang menjelaskan kepala sekolah sebagai supervisor artinya kepala sekolah berfungsi sebagai pengawas, pengendali, pembina, pengarah, dan pemberi contoh kepada para guru dan staf yang ada di sekolah. ${ }^{18}$ Oleh karena itu untuk meningkatkan kinerja guru salah satunya adalah guru bimbingan dan Konseling supervisi perlu dilakukan

Sebelum kegiatan supervisi dilaksanakan, seperti pada hasil penelitian di atas bahwa kepala sekolah melakukan kegiatan dalam bidang perencanaan, beliau merencanakan terlebih dahulu apa saja yang akan beliau supervisi setelah itu baru dibuat jadwal pelaksanaan supervisi. Perencanaan program supervisi yang di buat di dasarkan pada kebutuhan guru atau kebutuhan sekolah. Ini sejalan dengan pendapat Sergiovanni, 1987 dan Daresh, 1989 (dalam Aminah) yang menyatakan tingkat kemampuan, kebutuhan, minat, dan kematangan profesional serta karakteristik personal guru lainnya harus dijadikan dasar pertimbangan

${ }^{18}$ Herabudin. (2009) Adminisrasi dan Supervisi Pendidikan, (Bandung: Pustaka Setia) 
perencanaan dalam mengembangkan dan mengimplementasikan program supervisi akademik. ${ }^{19}$

Hal ini juga sesuai dengan pendapat Lisna dan Munastiwi, terdapat lima langkah utama dalam melakukan supervisi, yaitu: (1) Menetapkan tolok ukur, yaitu menentukan pedoman yang digunakan; (2) Mengadakan penilaian, yaitu dengan cara memeriksa hasil pekerjaan yang nyata telah dicapai;(3) Membandingkan antara hasil penilaian pekerjaan dengan yang seharusnya dicapai sesuai dengan tolok ukur yang telah ditetapkan; (4) Menginventarisasi penyimpangan dan atau pemborosan yang terjadi (apabila ada); dan (5) Melakukan tindakan korektif, yaitu mengusahakan agar yang direncanakan dapat menjadi kenyataan. ${ }^{20}$

Dari hasil penelitian diatas juga diketahui bahwa teknik yang dilakukan oleh kepala sekolah SMA Negeri 10 Banjarmasin pada saat melaksanakan supervisi adalah teknik individual/teknik perseorangan dimana pada saat melakukan supervisi kepala sekolah SMA Negeri 10 Banjarmasin melakukan 3 kegiatan yaitu; kunjungan kelas, observasi kelas dan wawancara perseorangan sebelum pandemic covid terjadi, tetapi setelah terjadi pandemic covid 19 melanda Banjarmasin kegiatan yang dilakukan hanya wawancara perseorangan saja berdasarkan laporan kinerja yang dikumpulkan oleh guru Bimbingan dan Konseling.

Wawancara perseorangan yang dilakukan oleh kepala sekolah sebagai supervisor dengan tujuan menghendaki adanya jawaban dari individu tertentu. Hal ini dapat dilakukan, pertama apabila ada masalah khusus pada individu guru yang penyelesainnya tidak boleh didengar oleh orang lain. Kedua, apabila supervisor ingin mengecek kebenaran data yang sudah dikumpulkan dari orang lain. Dalam hal ini teknik perseorangan adalah hal yang tepat agar orang yang diwawancara tidak terpengaruh oleh pendapat orang lain.

\section{Penutup}

Berdasarkan hasil penelitian dan pembahasan maka di peroleh Kesimpulan penelitian yang menunjukkan bahwa kepala sekolah SMA Negeri 10 Banjarmasin sudah sesuai dalam menjalankan tugas dan perannya sebagai supervisor sekolah dalam melaksanakan supervisi disekolah yang dipimpin dalam mensupervisi kinerja guru bimbingan dan konseling. Kepala sekolah telah berupaya secara berkelanjutan untuk melaksanakan supervisi yang terencana dan terjadwal untuk membantu guru dalam meningkatkan kinerja mereka. Kepala

\footnotetext{
${ }^{19}$ Siti Aminah. (2010). Kepala Sekolah Sebagai Supervisor Terhadap Kinerja Guru, dalam Media Sekolah, Edisi 57 Tahun III, 1-5 April

20 Ade Lisna dan Erni Munastiwi. (2020). Peran Kepala Sekolah Sebagai Supervisor Meningkatkan Profesionalisme Guru. Jurnal Pelita PAUD. Vol 5 No 1:7-13
} 
sekolah telah berupaya secara berkelanjutan untuk melaksanakan supervisi yang terencana dan terjadwal untuk membantu guru dalam meningkatkan kinerja mereka. Didalam melaksanakan supervisi kepala sekolah menggunakan teknik individual/perorangan dengan melaksanakan kegiatan supervisi,yakni kunjungan kelas, observasi kelas dan wawancara perseorangan.

Berdasarkan hasil penelitian yang peneliti lakukan maka peneliti akan mencoba memberikan saran-saran, meskipun saran ini bukan merupakan saran yang The Best Solution kepada pihak-pihak yang mempunyai kepentingan di dalamnya, antara lain yaitu: Kepala Sekolah bisa mempertimbangkan untuk membentuk tim yang di fungsikan untuk membantu dalam pembuatan perencanaan dan penjadwalan supervisi di sekolah, Hendaknya dalam pelaksanaan supervisi dilaksanakan secara berkala persemester/per 3bulan/perbulan jadi tidak hanya terjadwal saja, Kepala Sekolah hendaknya tidak hanya menggunakan teknik individual saja tapi juga ada saatnya menggunakan teknik kelompok dalam melaksanakan supervisi.

\section{Daftar Pustaka}

Ade Lisna dan Erni Munastiwi. (2020). Peran Kepala Sekolah Sebagai Supervisor Meningkatkan Profesionalisme Guru. Jurnal Pelita PAUD. Vol 5 No 1:7-13

Anggraini, S. (2017). Peran supervisi bk untuk meningkatkan profesionalisme guru Bk. In Prosiding Seminar Bimbingan dan Konseling (Vol. 1, No. 1, pp. 332-341).

Bowo, B. (2020). Peran Kepemimpinan Kepala Sekolah Sebagai Supervisor dalam Meningkatkan Kompetensi Guru di SMA Negeri 1 Ngronggot Kabupaten Nganjuk Tahun 2020. Dharma Pendidikan, 15(2), 93-106.

Fadhli, M. (2016). Kepemimpinan Kepala Sekolah Yang Efektif dalam Menciptakan Sekolah Efektif. Jurnal Tarbiyah, 23(1).

Fathur Rahman. (2009). Bimbingan dan Konseling Komprehensif; Dari Paradigma Menuju Aksi. Disampaikan pada Workshop Penyusunan Program BK Komprehensif bertempat di Ruang Sidang Utama Rektorat UNY, Kerjasama Prodi BK UNY dan PD ABKIN DIY. Yogyakarta: Universitas Negeri Yogyakarta.

Ginting, R. (2020). Fungsi Supervisi Kepala Sekolah Terhadap Kinerja Guru. JURNAL Edukasi Nonformal, 1(2), 88-93.

Hajati, K. (2010) Model Program peningkatan kompetensi konselor sekolah menengah atas berbasis standar kompetensi konselor Indonesia. Disertasi Doktor pada SPS UPI Bandung: tidak diterbitkan 
174 | Islamic Counseling: Jurnal Bimbingan dan Konseling Islam, Vol. 5, No. 2, 2021

Herabudin. (2009) Adminisrasi dan Supervisi Pendidikan, (Bandung: Pustaka Setia)

Jihad, A., \& Murniati, A. R. (2019). Hubungan motivasi kerja dan supervisi kepala sekolah dengan kinerja guru SMP Negeri di Kecamatan Babahrot Aceh Barat Daya. Jurnal Administrasi Pendidikan: Program Pascasarjana Unsyiah, 7(1).

Mangkunegara. (2011). Manajemen Sumber Daya Perusahaan. PT.Remaja Rosdakarya. Bandung

Natawidjaja, Rochman, (2009).Konseling Kelompok (Konsep Dasar dan Pendekatan),Bandung: Rizqi Press,

Nurfarida, S. F., \& Minsih, S. A. (2017). Kepemimpinan Kepala Sekolab Dalam Melaksanakan Program Pengembangan Sekolah Di SDIT Muhammadiyah AlKautsar Gumpang Tabun Ajaran 2016/2017 (Doctoral dissertation, Universitas Muhammadiyah Surakarta).

Permana, S. A. (2020). Peran Guru BK dalam Meningkatkan Keterampilan Belajar dan Motivasi Belajar Siswa. Syifaul Qulub: Jurnal Bimbingan dan Konseling Islam, 1(2), 61-69.

Raupu, S., \& Arifanti, D. R. (2019). Pelaksanaan Supervisi Pendidikan oleh Kepala Sekolah dalam Meningkatkan Profesionalisme Guru Bimbingan Konseling di SMP Negeri 8 Palopo. Kelola: Journal of Islamic Education Management, 4(1), 61-66.

Salma, P., \& Yusrizal, N. U. (2018). Pelaksanaan Supervisi klinis dalam Meningkatkan Kompetensi Profesional Guru di MAN Beureunuen. Jurnal Administrasi Pendidikan: Program Pascasarjana Unsyiah, 6(1).

Siti Aminah. (2010). Kepala Sekolah Sebagai Supervisor Terhadap Kinerja Guru, dalam Media Sekolah, Edisi 57 Tahun III, 1-5 April

Sugiyono.(2015) Metode Penelitian Pendidikan Pendekatan kuantitatif, Kualitatif, dan R\&D, (Bandung: Alfabeta).

Sutarto, S., Syafriyadin, S., \& Warlizasusi, J. (2019). Konseling Eklektik Islami untuk Mengubah Konsep Diri Waria. KONSELI: Jurnal Bimbingan dan Konseling (E-Journal), 6(1), 65-74.

Suwidagdho, D., Lestari, L., \& Dewi, S. P. (2017). Peran Pengawas BK untuk Meningkatkan Profesionalitas Guru Bimbingan dan Konseling. In Prosiding Seminar Bimbingan dan Konseling (Vol. 1, No. 1, pp. 137-143).

Vianda, D. (2015). Bimbingan dan Konseling dalam Pendidikan Formal. Jurnal Al-Taujib: Bingkai Bimbingan dan Konseling Islami, 1(1), 98-108. 